\title{
Detection of Chlamydia trachomatis DNA in patients with non-gonococcal urethritis using the polymerase chain reaction
}

\author{
G Ratti, A Moroni, R Cevenini
}

\begin{abstract}
A practical protocol using the polymerase chain reaction (PCR) was designed for detecting Chlamydia trachomatis in clinical samples. DNA was extracted from material collected on urethral swabs and used as substrate for the PCR. The target was a 600 basepair DNA segment of the multicopy plasmid that is common to all strains of the bacterium. Negative samples were checked for loss of DNA or presence of polymerase inhibitors by a second PCR, targeted to a conserved segment of the human genome. The whole procedure was tested on 216 men with nongonococcal urethritis (NGU). All patients were independently assessed by tissue culture isolation $(60$ positive samples) and a commercial immunoenzymatic assay. The PCR protocol, while sufficiently simple for routine application, was reliable and, for the diagnosis of urethritis, at least as good as tissue culture isolation.
\end{abstract}

Chlamydia trachomatis causes a wide spectrum of diseases, ${ }^{1}$ and it is very often the cause of non-gonococcal urethritis (NGU). Several procedures for its diagnosis are used in clinical practice, ${ }^{2}$ but it is widely accepted that a sensitive and at the same time widely available diagnostic assay has yet to be developed. ${ }^{2}$ Tissue culture isolation, which is considered the most reliable detection method so far, requires facilities and technical expertise that are not usually available in clinical laboratories. Furthermore, because tissue culture can only detect fully infectious chlamydiae, it is prone to interfering factors ${ }^{23}$ which compromise bacterial viability, usually during specimen collection and storage. There also seems to be a stage during the infection in which the bacterium can be detected using chemical techniques but not by cultural isolation. $^{4}$

A diagnostic method based on the extremely sensitive technique of DNA amplification by a polymerase chain reaction $(P C R)^{5}$ would therefore be very useful and PCR assays for the detection of $C$ trachomatis have been reported recently. ${ }^{6-9}$ We describe a protocol, designed for clinical routine use, which utilises a $C$ trachomatis specific PCR assay, and a control PCR test for $C$ trachomatis negative samples targeted to a conserved segment of the human DR- $\beta$ genes in the HLA class II region. ${ }^{10}$ This protocol was assessed on a group of 216 consecutive cases of non-gonococcal urethritis (NGU), 60 of which were culture positive for $C$ trachomatis.

\section{Methods}

Standard procedures for DNA manipulation were used throughout. ${ }^{11}$ Oligonucleotides were prepared with an automated DNA synthesiser model $380 \mathrm{~B}$, with reagents and procedures recommended by the manufacturers (Applied Biosystems Inc, Foster City, California, USA). All oligonucleotides were purified on $10 \%$ polyacrylamide/7M urea gels. ${ }^{11}$

The diagnostic PCR was targeted to the $7 \cdot 5$ kilo base plasmid which is common to all isolates of $C$ trachomatis, ${ }^{39-12}$ and is estimated to be present in five to 10 copies per chlamydial cell. ${ }^{12}$ Two amplification primers, Champ1: $5^{\prime}-$ CCAAAGCTATTCAAAATCGGAGCTCTAAGA-3' and Champ4: 5'-GTCTTCTGCTTACAATGCTCT TGCATATTA-3', were prepared. Their sequences are completely conserved in the plasmid variants so far described $^{14}$; they have similar $A+T$ and $G+C$ content, and they frame a segment of plasmid DNA which is 610-612 base pairs in length according to the serotype. ${ }^{14}$ This segment comprises a region which is probably the origin of replication and contains a base pair four-fold perfect repeat which is a convenient hybridisation target for a synthetic DNA probe. Accordingly, a 22 nucloeotide long oligonucleotide with the sequence of a repeat unit (Champ3: 5'-TTTGCAACTCTTGGTGGTAGAC-3') was synthesised as a probe, specific for the amplified DNA segment. This was used after $5^{\prime}$ end-labelling using $\left[\gamma-{ }^{32} \mathrm{P}\right] \mathrm{ATP}$ and T4 polynucleotide kinase, as described. ${ }^{11}$

Typical reaction mixtures, as used in the clinical study, contained the DNA template (variable amounts added in $20 \mu \mathrm{l}$ of water), PCR buffer $(10 \mathrm{mM}$ TRIS- $\mathrm{HCl}, \mathrm{pH} 8.3$ at $\left.25^{\circ} \mathrm{C}, 50 \mathrm{mM} \mathrm{KCl}\right), 200 \mu \mathrm{M}$ each of the four deoxy-nucleotide triphosphates (dNTPs) $1.5 \mathrm{mM} \mathrm{MgCl}_{2}, 1 \mu \mathrm{M}$ total oligonucleotide primers (25 pmol of each) and 2 IU of DNA polymerase, in a final reaction volume of $50 \mu \mathrm{l}$. We used native ( $T a q$ polymerase) or recombinant (Amplitaq) thermostable DNA polymerase from Thermus aquaticus (Perkin- 
Elmer Cetus, Norwalk, Connecticut, USA), PCR buffer and dNTPs provided with the GeneAmp PCR Reagent kits (Perkin-Elmer Cetus). Thirty amplification cycles (one cycle $=$ one minute at $94^{\circ} \mathrm{C}$, one minute at $45^{\circ} \mathrm{C}$, and one minute at $72^{\circ} \mathrm{C}$ ) were usually performed, using GeneAmp reaction tubes and an automatic DNA thermal cycler (Perkin-Elmer Cetus). Amplifications were terminated at $72^{\circ} \mathrm{C}$ for 15 minutes. Reaction products were analysed, in one fifth $(10 \mu \mathrm{l})$ of reaction mix, by electrophoresis in $(1 \%$ agarose $+1 \%$ Nusieve agarose) gels; FMC Marine Colloids, Rockland, Maine, USA).

For control PCR, two primers AR1 (5'-GGCGGTGACGGAGCTGGGGCG-3') and AR2 (5'-CGCCGCTGCACTGTGAAGCTC) were synthesised for the specific amplification of a 153 base pair segment of the DR- $\beta$ genes, in the HLA-class II region. ${ }^{10}$ The segment corresponds to amino acid residues 49 to 94 , encoded by the second exon of the DR genes. ${ }^{10}$ AR1-AR2 can amplify all known alleles of these genes; they were used in the same experimental conditions described above for PCR with Champ 1/4 primers.

The clinical specimens were taken from 17 to 37 year old men, attending the hospital's sexually transmitted diseases clinic, who presented with symptoms broadly grouped as "urethritis". These were as follows: dysuria, or urethral discharge, or a Gram stained smear showing four or more polymorphonuclear lymphocytes per microscopic field $(\times 1000$ magnification) and severity of symptoms were variable; information on the sexual behaviour of patients was not collected. Within this group 216 consecutive samples negative for gonococcal isolation, performed according to the Biocult-GC method (Orion Diagnostica, Espoo, Finland), were classified as NGU and were examined for chlamydial infection.

Specimens were obtained as endourethral cotton swabs. These were immersed in the appropriate medium or buffer in a sterile phial containing two small glass beads. After about an hour at room temperature and vortexing for one minute the swab was squeezed and withdrawn.

The enzyme linked immunoassay Chlamydiazyme (Abbott, Chicago, Illinois, USA) was performed according to the manufacturer's instructions.

Tissue culture was performed within a few hours of sample collection. McCoy cell monolayers treated with cycloheximide and a fluorescein labelled, species specific monoclonal antibody against major outer membrane protein were used as previously described. ${ }^{15}$

Swab material was dispersed, as described above, in $0.8 \mathrm{ml}$ of lysis buffer ( $10 \mathrm{mM}$ TRIS$\mathrm{HCl}, \mathrm{pH} 7 \cdot 5,150 \mathrm{mM} \mathrm{NaCl}, 2 \mathrm{mM}$ EDTA, $0.6 \%$ sodium dodecyl sulphate). After treatment with proteinase $\mathrm{K}(200 \mu \mathrm{g} / \mathrm{ml})$ at $37^{\circ} \mathrm{C}$ for a few hours the sample was extracted with phenol/chloroform ${ }^{11}$ and resuspended in $100 \mu 1$ of water. DNA (1-2 $\mu \mathrm{g})$ could be usually obtained. A stock of $2 x$ reaction-mix solution, containing all the PCR reagents but also sample DNA and DNA polymerase, was previously prepared and tested by PCR with and without plasmid DNA to check for performance and absence of contamination. Aliquots of this mixture $(25 \mu \mathrm{l})$ were kept frozen in separate GeneAmp tubes. To each of these, just before use, were added $20 \mu \mathrm{l}$ of DNA sample and $2 \mathrm{U}$ of $T a q$ polymerase (final reaction volume $50 \mu \mathrm{l}$ ). Precautions ${ }^{16}$ were taken to prevent accidental contamination of samples, but the use of separate rooms for different operations or special techniques for delivering the reagents were not adopted. Standard type pipettes (Pipetman; Gilson, Villiers-le-Bel, France), rather than positive displacement pipettes were used; the use of separate sets of micropipettes and rinsing of pipette outlets was essential, however. Furthermore, blank "reporter" samples (containing DNA from McCoy cells not infected with $C$ trachomatis) were interspersed among clinical samples and processed in parallel.

After 30 PCR cycles with Champ1/4 primers $10 \mu \mathrm{l}$ of reaction mix were examined by electrophoresis and ethidium bromide fluorescence in ultraviolet light. ${ }^{11}$ A control PCR test was performed on $C$ trachomatis negative samples with separate $10 \mu \mathrm{l}$ aliquots of original samples and the primers AR1-AR2, as described above, to check for the presence of adequate amounts of DNA and absence of inhibitors of Taq DNA polymerase.

\section{Results}

The PCR was targeted to the $C$ trachomatis common plasmid ${ }^{3912-14}$ and was initially tested using several kinds of samples prepared in the laboratory. These contained either $0 \cdot 1-1 \mathrm{pg}$ of pUC8-PCTD, a recombinant pUC8 plasmid comprising the entire chlamydial plasmid (serotype D variant ${ }^{14}$ ), or $10-100$ ng of nucleic acids extracted from infected HeLa cells, or pUC8-PCTD added to $1 \mu \mathrm{g}$ of human lymphocyte DNA. Samples of total nucleic acids extracted from urethral swabs of infected patients were also used for PCR optimisation.

Different primer hybridisation temperatures, $\mathrm{Mg}^{+-}$, and primer concentrations were tested on several types of samples (data not shown). For positive clinical samples the $\mathrm{Mg}^{+}{ }^{+}$optimal concentration, with $1 \mu \mathrm{M}$ Champ $1 / 4$ primers, was close to $1.5 \mathrm{mM}$. PCR conditions were eventually standardised.

Normally a single major electrophoretic band of the expected size (about 600 base pairs) was obtained (figure) with no interfering artefactual PCR products; only occasionally with some clinical samples could a few background bands be observed. The identity of the amplified DNA segment was confirmed by hybridisation with Champ3, 5' end-labelled with ${ }^{32} \mathrm{P}$, on Southern blots ${ }^{11}$ or in a dot-blot assay (results not shown).

Triplicate sets of samples containing $1 \mu \mathrm{g}$ of human lymphocyte DNA and tenfold dilutions of pUC8-PCTD were amplified by 30 PCR cycles and the products detected by electrophoresis of $10 \mu \mathrm{l}$ of reaction mixture and ethidium bromide staining (ETB-PCR). A clearly detectable DNA band was obtained from samples containing, before amplification, 
Typical results of the PCR assay on clinical samples. Lane 1: molecular size marker, digested with HaeIII, RF-DNA of Ltd). Lanes 2 and 3: culture positive samples amplified with Champ1/4 primers. Lanes 4 to 7 . culture negative samples primers (lanes 4 and 5 ) and with $A R 1 / 2$ primers (lanes 6 and 7) as a control. The sizes of the amplified DNA segments correspond to about 600 base pairs (diagnostic band) and 150 base pairs (control band). phage $\varphi X-174$ (Biolabs, amplified with Champ1/4

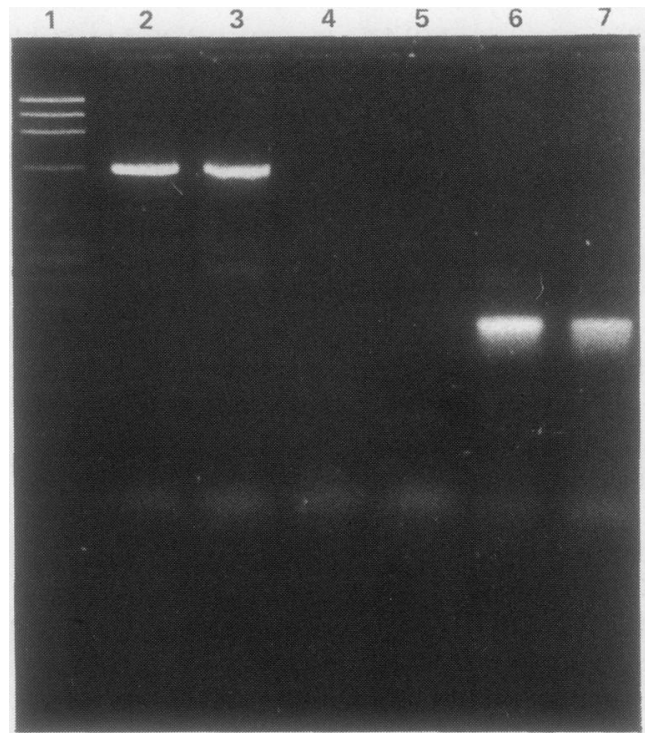

more than $10^{3}$ plasmid molecules-that is, about $6 \times 10^{-16} \mathrm{~g}$ of target DNA (0.6 kilo base segment). Samples with lower initial amounts gave results which were irreproducible and, when positive, too feint for confirmatory scoring. With a detection limit of $10^{-8} \mathrm{~g}$ for a DNA band stained with ethidium bromide, these results indicate an amplification of the order of $10^{8}$ (about $75 \%$ of the theoretical value for 30 cycles). Similarly, with ETB-PCR, Kaneko et al detected a minimum of $10^{-14} \mathrm{~g}$ of cloned hepatitis $B$ virus DNA. ${ }^{16}$ Considering the known sensitivity limits of the various techniques, these results also agree with previous reports of detection of a single copy of a 150 base pair target DNA, in background DNA from $10^{5}-10^{6}$ human cells. This was achieved after 40 cycles and detection by filter hybridisation with a 32P-labelled probe on multiple replicas of the sample (to account for the random nature of early PCR events at extremely low concentrations). ${ }^{5}$

A protocol based on the above $P C R$ assay was designed for clinical routine use. Its main features were the following: (1) Nucleic acids were extracted from urethral swabs and dissolved in $100 \mu \mathrm{l}$ of water. One fifth of this solution was used for amplification: this aliquot allows for two PCR tests and leaves enough specimen for storage or repetition of the assays (in case of contrasting results after comparison with other diagnostic methods in a doubleblind procedure). (2) For the sake of simplicity, the amount of DNA in the individual samples

Table 1 Summary of clinical results

\begin{tabular}{rlll}
\hline No of samples & Cell culture & Immunoassay & Plasmid PCR \\
\hline 140 & - & - & - \\
56 & + & + & + \\
0 & + & + & - \\
0 & + & - & + \\
4 & + & + & + \\
3 & - & + & - \\
11 & - & $70+$ & $65+$ \\
2 & $60+$ & $146-$ & $151-$ \\
216 & $156-$ & & \\
\hline
\end{tabular}

Table 2. Assessment of PCR test compared with Tissue culture isolation

\begin{tabular}{|c|c|c|}
\hline & \multicolumn{2}{|c|}{ Tissue culture } \\
\hline & Positive & Negative \\
\hline \multicolumn{3}{|l|}{ PCR: } \\
\hline $\begin{array}{l}\text { Positive } \\
\text { Negative }\end{array}$ & $\begin{array}{r}60 \\
0\end{array}$ & $\begin{array}{r}5 \\
151\end{array}$ \\
\hline \multicolumn{3}{|c|}{$\begin{array}{l}\text { Sensitivity }=\text { (positive }[\mathrm{PCR} \text { and TC]/positive TC }) \times 100= \\
(60 / 60) \times 100=100 \% .\end{array}$} \\
\hline \multicolumn{3}{|c|}{$\begin{array}{l}\text { Specificity }=(\text { negative }[\mathrm{PCR} \text { and TC]/negative TC }) \times 100= \\
(151 / 156) \times 100=96.8 \% .\end{array}$} \\
\hline
\end{tabular}

was not directly estimated, but $C$ trachomatis negative samples were further assessed by amplifying a conserved DNA segment of human DNA: this ensured presence of adequate amounts of DNA in the sample and absence of polymerase inhibitors or nuclease contamination-that is, correct processing of the specimen. (3) The PCR was limited to 30 cycles and scoring was done on one fifth of the amplified sample, on the basis of presence or absence of a single electrophoretic band, about 600 base pairs in length and clearly detectable by ethidium bromide fluorescence.

This protocol was assessed on 216 consecutive cases of NGU. Three specimens were collected from each patient and assessed in parallel by Chlamydiazyme immunoassay, cultural isolation, and PCR. For ethical and technical reasons, each test was performed on a different specimen rather than dividing each sample into three parts. The specimen for the PCR test was the last; all the material from the first two swabs was used for the officially approved diagnostic tests.

Typical positive and negative PCR results are shown in the figure. All $C$ trachomatis negative samples produced an intense electrophoretic band when amplified with the HLA control primers (figure, lanes 6,7 ). The results are summarised in tables 1 and 2 .

\section{Discussion}

The PCR followed by detection with ethidium bromide fluorescence (ETB-PCR) yielded a single electrophoretic DNA band which correlated with the presence of the chlamydial common plasmid in the sample. The assay permitted a detection limit of the order of $10^{3}$ target molecules per sample before amplification. This can be assumed to correspond to $10^{2}$ chlamydiae. ${ }^{12}$ In other words, if performed on one fifth of DNA extracted from a clinical swab, the ETB-PCR permits detection of about 500 bacteria in the whole sample-a figure compatible with one chlamydial cytoplasmic inclusion of average size, even allowing for loss of DNA during sample extraction.

Greater sensitivity may be achieved by increasing the number of cycles and adopting more sensitive detection methods, such as using a ${ }^{32} \mathrm{P}$-labelled probe. This was not attempted, however, as such procedures would not be convenient for routine diagnosis, which was our primary interest. Furthermore, detection of a very low number of target molecules 
(1000 to 1) may require a greater degree of sample manipulation for reliability-for example, reagent variation during $\mathrm{PCR}^{17}$ or testing each sample multiply to compensate for the random nature of early events. ${ }^{5}$ In the absence of full automation this is also undesirable because it increases the chance of sample contamination, probably the major problem in PCR when used for diagnosis.

In previous reports PCRs for the detection of $C$ trachomatis were targeted to a conserved segment of the chromosomal MOMP gene, ${ }^{7}$ or to a ribosomal RNA gene, ${ }^{8}$ or to the 7.5 kilo base common plasmid. ${ }^{9}$ Reported PCR sensitivities varied from as low as $10^{6}-10^{7}$ elementary bodies ${ }^{7}$ to as high as $10^{-17} \mathrm{~g}$ (with 40 PCR cycles) of total chlamydial DNA, ${ }^{9}$ showing detection on laboratory samples of amounts of total chlamydial DNA equivalent to one plasmid molecule, or even less. The random behaviour of PCR at such extreme target dilutions is not discussed, and some of the data seem to imply a target amplification close to or even greater than theoretical values. Nevertheless, the overall performance of the PCR test previously described ${ }^{9}$ with clinical samples (on 220 genital and eight ocular specimens, with a total of 26 culture positive results) correlates well with our findings, with a reported sensitivity of $100 \%$ and a specificity of $93 \%$ compared with cell culture isolation.

Because the described ETB-PCR assay was considered sufficiently convenient and sensitive to be tested in a clinical study, it was implemented in a practical protocol, which was assessed on 216 patients. This was a group of cases of NGU, which, although not very rigorously selected, was nevertheless likely to comprise a sufficiently high percentage of $C$ trachomatis infections. The 60 positive cases represent $27.8 \%$ of the total. As criteria for classifying NGU may be more or less rigorous in different clinics, this value is not in contrast with other studies reporting prevalence rates of $30-60 \%$ for cases of NGU. ${ }^{18}$ Variability in isolation rates can be due to a variety of factors, ${ }^{18}$ one of which is, of course, the sensitivity of the isolation procedure. Given long standing general experience with this technique in our hospital and the fact that cell culture was performed within a few hours of specimen collection, the heterogeneity of the NGU group was probably the predominant reason for a comparatively lower percentage of isolation of $C$ trachomatis.

The results indicated that even when performing, for ethical reasons, the PCR test on the third swab (presumably depleted of infected cells compared with the first two) the PCR was never negative when at least cultural isolation was positive. The use of only one fifth of the sample per PCR test was a choice convenient for this study because it allowed for duplicate $C$ trachomatis detection and control assays, plus an aliquot for storage. A greater sensitivity could be attained, however, by increasing the aliquot or, more importantly, the quality of the sample to be tested. For instance, in future work, if an approved PCR assay were the only one to be performed, two swabs could be collected and material from one whole swab used per assay, while keeping the second specimen for a possible duplicate or control test.

In five cases PCR results were positive when cultural isolation was negative. Three of these were also positive by immunoassay. When dealing with a potentially more sensitive test than the reference one, it is difficult to discriminate between possible false positive results and instances of sensitivity much greater than the standard. The negativity of blank control samples included throughout the study would argue against positivity due to contamination, but this point will probably be clarified only with the support of further clinical data.

A comparison of PCR results with cultural isolation indicates a sensitivity of $100 \%$ and a specificity of $96.8 \%$. It should be noted, however, that an assay with a sensitivity which is greater than that of the standard will appear less specific than it actually is. If, in contrast, cultural isolation were to be assessed against PCR, $92.4 \%$ sensitivity and $100 \%$ specificity values would be obtained. In any case ETBPCR assessment of NGU, in our opinion, could safely substitute tissue culture methods.

These considerations explain the choice of initially assessing the reliability of the PCR protocol on a group of NGU cases of variable severity, for which cultural isolation was likely to be sufficiently close to a real "goldstandard". With other diseases, in which cultural isolation has a poor performance-for example, $50 \%$ sensitivity reported for ocular specimens ${ }^{4}$-or, when chlamydial infection is suspected but isolation is usually negative, a good PCR test would be expected to detect the pathogen unlike other tests and in the absence of a recognised standard. It is therefore our opinion that such studies represent an important goal for PCR diagnosis, but procedures should first be assessed in a safer context, like the one reported here.

We thank S Ricci for oligonucleotide synthesis, $M$ Comanducci and Dr S Giannelli for help during PCR development, and referees for valuable comments.

1 Moulder JW, Hatch TP, Kuo CC, Schachter J, Storz J. Chlamydia. In: Bergey's manual of systematic bacteriology. Vol 1. Baltimore: Williams \& Wilkins, 1984:729-39.

2 Barnes RC. Laboratory diagnosis of human chlamydial infections. Clin Microbiol Rev 1989;2:119-36.

3 Dean D, Palmer L, Chet Raj Pant, Courtright P, Falkow S, O'Hanley P. Use of a Chlamydia trachomatis DNA probe for the detection of ocular chlamydiae. J Clin Microbiol 1989;27:1062-7.

4 Schachter J, Moncada J, Dawson CR, et al. Nonculture methods for diagnosing chlamydial infection in patients with trachoma: a clue to the pathogenesis of in patients with trachoma: a clue to the path
$J$ Infect Dis $1988 ; 158: 1347-52$.

5 Saiki RK, Gelfand DH, Stoffell S, et al. Primer-directed enzymatic amplification of DNA with a thermostable DNA polymerase. Science 1988;239:487-91.

6 Dean D, Pant CR, O'Hanley P. Improved sensitivity of a modified polymerase chain reaction amplified DNA probe in comparison with serial tissue culture passage for detection of Chlamydia trachomatis in conjunctival specimens from Nepal. Diagnost Microbiol Infect Dis 1989;12:133-7.

7 Dutilh B, Be'be'ar C, Rodriguez P, Vekris J, Bonnet J, Garret $M$. Specific amplification of a DNA sequence common to all Chlamydia trachomatis serovars using the polymerase chain reaction. Res Microbiol 1989;140:7-16.

polymerase chain reaction. Res Microbiol 1989;140:7-16.
8 Pollard DR, Tyler SD, Ng CW, Rozee KR. A polymerase chain reaction (PCR) protocol for the specific detection of
chlamydia spp.

9 Ostergaard L, Birkelund S, Christiansen G. Use of 
polymerase chain reaction for detection of Chlamydia trachomatis. J Clin Microbiol 1990;28:1254-60.

10 Bell JI, Denney D Jr, Foster L, Belt T, Todd JA, McDevit HO. Allelic variation in the DR subregion of the human major histocompatibility complex. Proc Natl Acad $S$ $U S A$ 1987;84:6234-8.

11 Maniatis T, Fritsch EF, Sambrook J. Molecular cloning: $A$ laboratory handbook. 2nd edn. New York: Cold Spring Harbor Laboratory, 1989.

12 Palmer I., Falkow S. A common plasmid of Chlamydia trachomatis. Plasmid 1986;16:1-11.

13 Horn JE, Hammer ML, Falkow S, Quinn TC. Detection of Chlamydia trachomatis in tissue culture and cervical scrapings by in situ DNA hybridization. J Infect Dis 1986;153:11

14 Comanducci M, Ricci S, Cevenini R, Ratti G. Diversity of the chlamydial common plasmid in biovars with different pathogenicity. Plasmid 1990;23:149-54.

15 Cevenini R, Donati M, Sambri V, Rumpianesi F, La Placa M. Reactivity of elementary and reticulate bodies of Chlamydia trachomatis LGV2 with monoclonal antibodies specific for the major outer membrane protein. FEMS Microbiol Letts 1987;42:47-51.

16 Kaneko S, Miller RH, Feinstone SM, et al. Detection of serum hepatitis B virus DNA in patients with chronic hepatitis using the polymerase chain reaction assay. Proc hepatitis using the polymerase chain
Natl Acad Sci USA 1989;86:312-6.

17 Ruano G, Fenton W, Kidd KK. Biphasic amplification of very dilute samples via 'booster' PCR. Nucleic Acids Res 1989;17:5407.

18 Oriel JD, Ridgway GL. In: Genital Infections by Chlamydia trachomatis. London: E Arnold, 1982:41-52. 